\title{
INCOMPLETUDE E CONTINUIDADE: ARRANJOS SISTÊMICOS NAS IMAGENS PARA PRODUÇÃO DE SENTIDO NA WEBSÉRIE DE TEATRO DE FIGURAS O BEM-AMADO
}

\author{
Gabriela Boccardi Mendes ${ }^{1}$ \\ Paulo César Balardim Borges ${ }^{2}$
}

RESUMO: Este artigo trata de como determinados recursos das linguagens da HQ do cinema e do teatro de figuras operam, sobrepostas, na produção de sentido da websérie $O$ Bem-Amado (Cia. Caras de Bonecos) e sobre como nossa cognição visual auxilia essa produção.

Palavras-Chave: Imagem. Teatro de figuras. HQ. Websérie. O Bem-Amado.

ABSTRACT: This article concerns how certain media resources from comic books, cinema and paper theater operate, overlapped, in the production of meaning of the webseries O Bem-Amado (The Beloved/ Caras de Boneco Company) and about how our visual cognition supports this production.

Keywords: Image. Paper theater. Comic books. Webseries. O Bem-Amado.

\section{INTRODUÇÃO}

A websérie $O$ Bem-Amado foi produzida no ano de 2021 e congregou o projeto de pesquisa Diálogos entre os elementos narrativos e poéticos do Teatro de Figuras com as produções audiovisuais (PPGAC-CEART-UDESC) com o trabalho da companhia de teatro Cia. Caras de Bonecos (Florianópolis/SC), obtendo o financiamento do Edital Campus de Cultura 2019 (CEART-UDESC).

Baseada na obra do dramaturgo brasileiro Dias Gomes, a história, dividida em sete episódios disponíveis no canal da companhia no Youtube apresenta Odorico Paraguaçu, candidato a prefeito da cidade fictícia de Sucupira, no interior da Bahia. Odorico quer

\footnotetext{
I Mestranda em Teatro (Centro de Artes CEART - Universidade do Estado de Santa Catarina- UDESC). Bacharel em Teatro (UFRGS - Universidade Federal do Rio Grande do Sul).

${ }^{2}$ Professor Associado na área de Prática Teatral - Teatro de Animação, no Departamento de Artes Cênicas e no Programa de Pós-Graduação em Teatro do Centro de Artes - CEART da Universidade do Estado de Santa Catarina - UDESC. Postdoc em Teatro de Animação (Université Paul Valéry-Montpellier III/2019), Doutor em Artes Cênicas (PPGT - UDESC/2013), Mestre em Artes Cênicas (PPGAC - UFRGS/2008), licenciado em Letras - Língua Portuguesa e Literatura Brasileira (ULBRA/2007).
} 
inaugurar um cemitério para o município que, desprovido de terreno para tal fim, tem que enterrar seus mortos na cidade vizinha.

Para representar essa história, foram utilizados personagens bidimensionais, figuras planas de aproximadamente $14 \mathrm{~cm}$ cada, feitas de papel, além de maquetes de cenários e o recurso de edição de imagens. Dessa forma, a pesquisa centrou-se em torno da relação de linguagem entre o Teatro de Figuras, as histórias em quadrinhos (HQs) e o audiovisual, refletindo sobre como a produção de sentido acontece na mescla dessas mídias, absorvendo características de cada uma delas e criando um produto artístico híbrido. A partir dessa premissa, faremos uma análise de como a união desses três recursos conduz a narrativa da série, levando em consideração o ponto de vista do espectador ao entendê-lo como co-autor da obra. A primeira parte deste artigo será dedicada às reflexões acerca da participação do observador na composição da obra de arte, aproximando teorias de Ernst Hans Gombrich de aspectos da teoria da Gestalt. Em seguida, faremos uma exposição teórica das linguagens envolvidas na criação da websérie, apontando suas principais características e como elas estruturam o trabalho e, por fim, observaremos de que maneira a sobreposição destas linguagem atua como responsável pela produção de sentido.

\section{O OBSERVADOR COMO COAUTOR DA IMAGEM}

Ao colocarmos uma imagem após a outra, cada uma delas contendo informações específicas, nosso cérebro tende a unir estas informações para dar-lhes um sentido a partir de nossas experiências e das imagens que já conhecemos. A maneira como nós entendemos as formas visuais graças a uma ação natural do cérebro pode ser melhor compreendida através dos estudos da Gestalt. Segundo esta teoria, existem padrões de comportamento visual denominados Princípios da Gestalt. Desses padrões, a continuidade nos permite projetar as razões desta capacidade e completude:

Quando eu vejo uma parte de um objeto, ocorre uma tendência à restauração do equilíbrio da forma, garantindo o entendimento do que estou percebendo. Esse fenômeno da percepção é norteado pela busca de fechamento, simetria e regularidade dos pontos que compõem uma figura (objeto). Os fenômenos deste tipo encontram sua explicação naquilo que os psicólogos da Gestalt descrevem como a lei básica da percepção visual: "qualquer padrão de estímulo tende a ser visto de tal modo que a estrutura resultante é tão simples quanto às condições dadas permitem" (BOCK, 1999, p. 4). 
Ana Maria Bock afirma que nosso cérebro, antes de perceber as partes de uma imagem, observa sua totalidade. Refletindo sobre este fato e colocando-o em relação às artes, quando uma obra se mostra "incompleta" ou exige de nós uma interpretação mais sofisticada, ela está solicitando nossa capacidade imaginativa para que possamos completála em nossas mentes. Ernst Gombrich (1909-200I), em sua publicação Arte e Ilusão, reflete sobre a participação do público no fazer artístico. Segundo o autor, a ciência de que o espectador pode não apenas perceber uma obra, mas também participar da construção de seu significado é fundamental para entendermos o desenvolvimento da história da arte.

O artista dá ao observador "mais o que fazer": ele o atrai para o círculo mágico da
criação e lhe permite experimentar um pouco do frêmito do "fazer", que foi um
privilégio do artista. É o movimento decisivo, crucial que conduz essas charadas
visuais da arte do século XX, que desafiam o nosso engenho e nos fazem buscar
nas nossas próprias mentes o não expresso, o inarticulado. (GOMBRICH, 2007,
p. I69.).

Nossas mentes completam o que a obra "falha" em nos mostrar. Essa experiência é compartilhada por diversas formas artísticas cujo meio fundamental de expressão é a imagem. De acordo com o quadrinista Scott McCloud, "nossa percepção da realidade é um ato de fé baseado em meros fragmentos. Esse fenômeno de observar as partes mas perceber o todo é chamado de conclusão" (MCCLOUD, 1995, p. 63). O autor defende que esta capacidade é intensamente utilizada na arte das histórias em quadrinhos (HQ), meio no qual "o público é colaborador consciente e voluntário, e a conclusão é o agente da mudança, tempo e movimento" (MCCLOUD, 1995, p. 65). O leitor de quadrinhos precisa completar informações o tempo todo; na simples ação de saltar o olhar de um quadro para outro, a conclusão já se faz necessária, pois entre os quadros existe um vão, um espaço físico em branco que separa uma ação da outra. E é este espaço que precisa ser preenchido com a nossa imaginação. As imagens de uma HQ representam apenas determinados marcos espaço-temporais, deixando implícitas todas as sequências de desenvolvimento das ações entre um marco (quadro) e outro. É a inferência do leitor, a partir de certos dados (paradigmas, ou "pistas"), que estabelecerá o elo entre as duas imagens dentro de um eixo contíguo.

Retornando a Gombrich, notamos que o historiador apoia sua teoria no estudo de obras que não tem uma sequência de informações, como acontece nos quadrinhos; seus exemplos vão de Donatello a Manet, mas estamos falando aqui de quadros únicos cuja 
imagem omite determinadas informações. McCloud estende seu olhar para a conclusão de sequências de imagens, entendendo o leitor como co-autor de suas narrativas cada vez que o quadrinista "esconde" informações do público entre um quadro e outro. Ambas teorias defendem a posição de co-autor do observador, mas em diferentes circunstâncias.

Ele (Manet), usa a própria ambiguidade de suas formas fugidias para sugerir uma variedade de interpretações e para compensar dessa forma a ausência de movimento na pintura (...) (GOMBRICH, 2007, p. I8I).

As pinceladas de Manet formam paisagens irregulares e disformes, porém sempre inteligíveis, para que possamos observar a preocupação do artista com os aspectos mais transitórios e com "as características mais efêmeras da realidade visual” (GOMBRICH, 2007, p.I8I). O contexto de A Amazona, (Manet, 1875) por exemplo, nos dá apenas uma ideia de onde a mulher está: pode ser um bosque, uma estrada, uma fazenda. O observador não tem a informação precisa, necessitando, portanto, imaginar o lugar onde a situação apresentada na obra acontece.

Figura I - Edouard Manet, A amazona - retrato de Marie Lefébure.

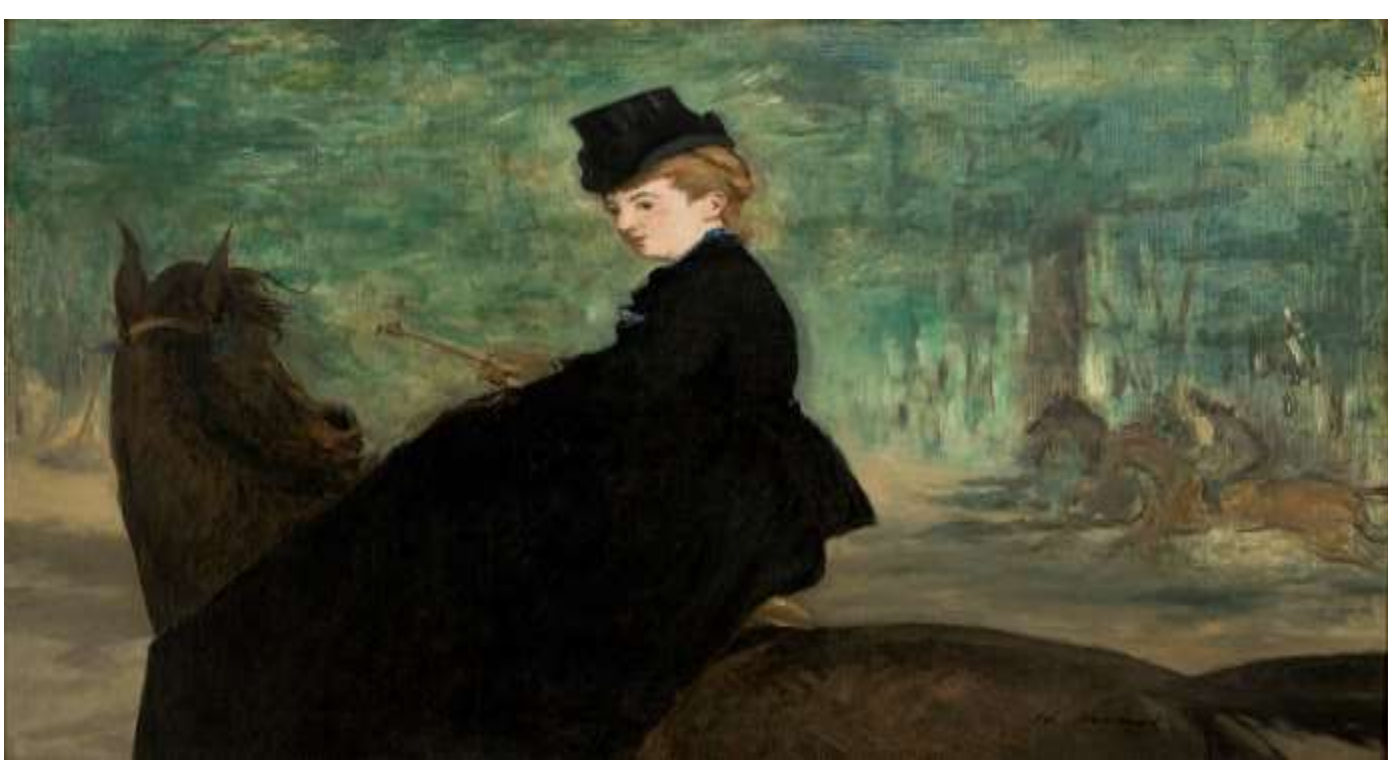

Fonte:https://artsandculture.google.com/asset/the-amazon-portrait-of-marie lef\% $\mathrm{C}_{3} \%$ A9bure/mwFaQhUuqr_H5Q?hl=pt (acesso em ro/or/2022)

O pintor nos apresenta contornos em suas paisagens provocando nossa habilidade visual de percebê-los enquanto forma e nomeá-los de acordo com nossas experiências. Este recurso pode ser melhor compreendido uma vez que entendemos o princípio da figura- 
fundo. Quando uma imagem nos é exibida, nossa primeira reação é tentar simplificá-la ao identificar uma figura central para então colocá-la em contraponto com os demais elementos da imagem, ou seja, seu fundo. Ao nos depararmos com uma imagem como o clássico vaso de Rubin, por exemplo, cuja ilusão visual nos apresenta duas imagens centrais, nosso cérebro consegue percebê-las uma de cada vez, causando uma certa confusão visual assim que assimilamos a existência da segunda forma.

\section{Figura 2 - O vaso de Rubin}
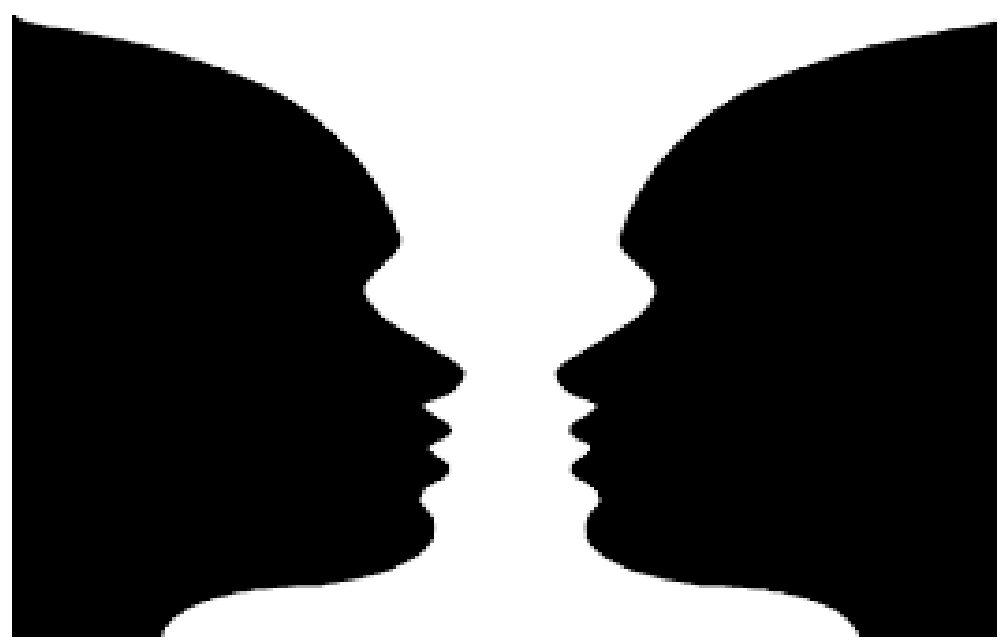

Fonte:https://www.udesc.br/arquivos/ceart/id_cpmenu/7177/Artigo_2_Gestalt_e_Semiotica_Visual_1559150 7812472_7177.pdf (acesso em 10/or/2022)

Os traços da imagem precisam estar bem delineados para que a ilusão ocorra. Suas formas sugerem caminhos para nossa imaginação - mais precisos na imagem de Rubin, mais abstratos na obra de Manet, mas o que devemos observar aqui é a capacidade de completar e interpretar uma imagem.

Figura 3 - Fonte: McCloud, Scott, Desvendando os quadrinhos, pg 67.
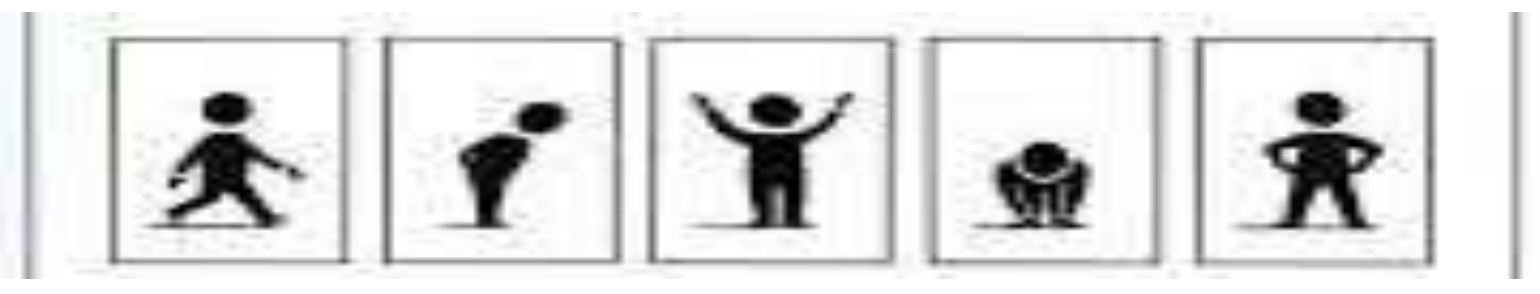
Embora esse tipo de inferência também ocorra na arte sequencial, esta ainda apresenta outro grau de complexidade ao inserir a dinâmica da evolução do tempo para a construção do sentido. McCloud afirma que um quadro, em uma HQ, "fragmenta tempo e espaço, oferecendo um ritmo recortado de momentos dissociados" (I995, p.67), ou seja, dividimos a história em partes e deixamos a cargo do leitor montá-la, como um quebracabeças. Dessa forma, provocamos a ilusão do movimento. O efeito de retenção da imagem em nosso cérebro, por exemplo, já foi amplamente utilizado por dispositivos précinemáticos, dentre eles o zootropo, o praxinoscópio e o taumatrópio. No cinema, exercemos este poder de conclusão o tempo todo. Os filmes analógicos consistem em fotos (quadros) mostradas por um projetor, cuja velocidade da projeção de 24 frames por segundo (fps) permite que aquelas nos dêem a impressão de estarem em movimento. Ao longo da história da sétima arte, do cinetoscópio de William Dickson (1889), ao cinematógrafo de Leon Bouly (1892), patenteado pelos irmãos Lumière e exibido pela primeira vez em 1895, outros recursos passaram a ser utilizados no intuito de instigar a imaginação do espectador, principalmente a partir da visão espetacular de George Méliès, nos primeiros anos do século XX.

O ilusionista trouxe inúmeros recursos das artes cênicas para seus filmes. Em Viagem à Lua (1902), Méliès transporta seu público pelo espaço sideral por meio dos imensos cenários com os quais trabalhava em suas gravações. Sua grande descoberta foi a "mágica” através da montagem cinematográfica, pois "criou diferentes truques visuais, tais como o stop-motion, o slow-motion, o dissolve, o fade-out, a sobreposição e a dupla exposição" (SZAFIR, BARROSO, 2019, p.55) . Cada um destes recursos da câmera proporciona efeitos sobre a imagem que tem a capacidade de suscitar emoções e pensamentos, podendo conduzir a narrativa mais precisamente de acordo com as ideias da produção e direção e possibilitando tornar realidade na tela universos fantásticos. A forma como Méliès conduziu a edição de seus filmes revolucionou o fazer cinematográfico, pois graças a sobreposição de linguagens o público pôde entrar no mundo das fadas (O Reino das Fadas, 1903), ver o artista multiplicar sua cabeça deixando as "cópias" sobre uma mesa, (O homem com a cabeça de borracha, I90I) bem diante de seus olhos. Entre as décadas de i89o e igro, Méliès produziu mais de 400 filmes com efeitos de mágica e temáticas burlescas. A edição 
de suas cenas era feita através dos recortes e da colagem dos rolos, e a coloração era feita à mão, com lápis de cor.

Figuras 4 e 5 - Imagens do filme Voyage dans la Lune, de Georges Méliès.
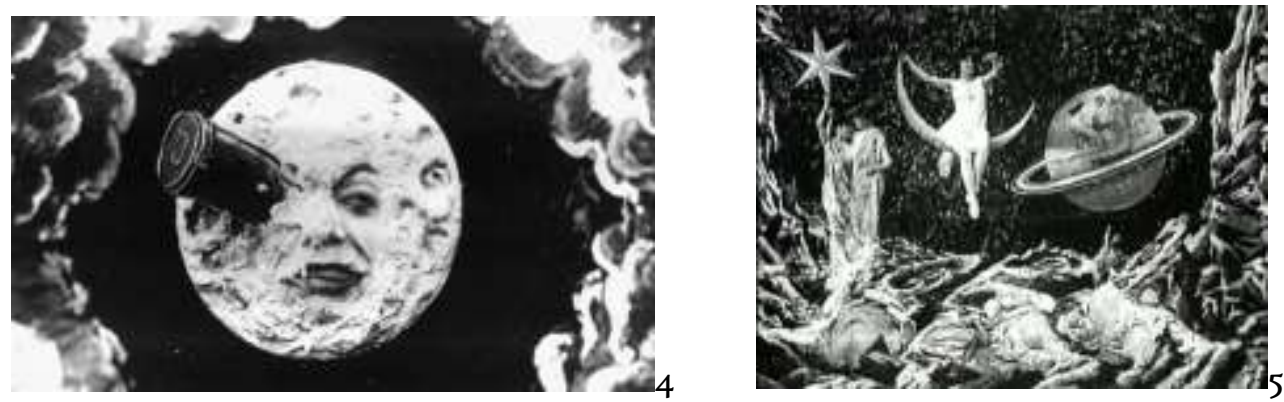

Fonte: https://publicdomainreview.org/collection/le-voyage-dans-la-lune-1902/

A partir de sua obra, podemos entender que a montagem cinematográfica opera a produção de sentido utilizando da justaposição de imagens, contando com a nossa percepção visual para unir estas imagens e dar-lhes um significado enquanto um todo. Contemporâneo ao trabalho de Méliès, o efeito cinematográfico desenvolvido pelo artista Lev Kuleshov se utiliza desta justaposição de imagens para dar significado à cena.

O experimento feito por Kuleshov mostra o ator Ivan Mozzhujin com a mesma expressão facial e encaixa na sequência três imagens diferentes: uma mulher deitada no sofá, uma criança em um caixão e um prato de sopa. Ao perceber estas imagens dentro de uma sequência, ficamos sugestionados a concluir, mesmo sem nenhuma alteração na expressão facial do ator, que este sente desejo, tristeza e fome, respectivamente. Graças a justaposição de imagens, é possível inferirmos os desejos das personagens.

Figura 6 - Imagem ilustrativa do Efeito Kuleshow.

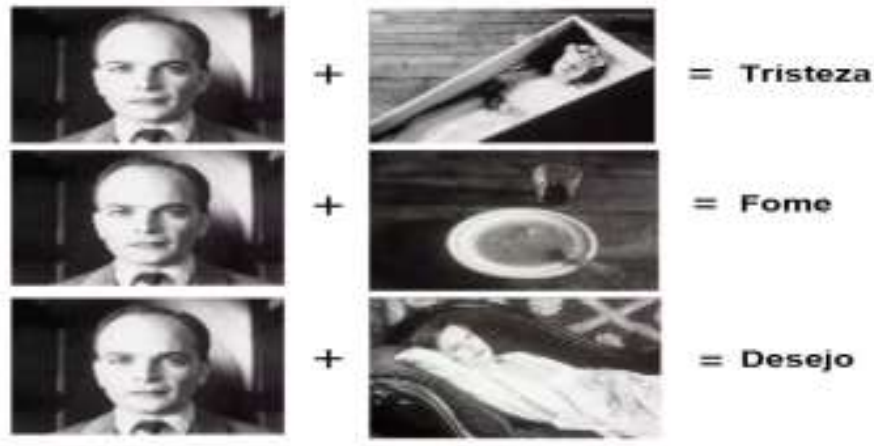

Fonte::https://cinemascope.com.br/colunas/efeito-kuleshov-ou-porque-os-russos-nao-brincam-em servico/(acesso em ro/ol/2022) 
No entanto, é importante observar o contexto da obra e sua função fundamental na assimilação destas imagens. Entendemos o significado das expressões faciais do ator através da justaposição, sim, mas "o contexto como um todo parece propiciar um delineamento de maior clareza diante de possíveis ambiguidades na expressão facial, quando comparado à análise em isolado". (URTADO, 2020, p.33). Para além da justaposição, as demais linguagens que compõem a cena e que portanto auxiliam na condução da narrativa, facilitam o entendimento da expressão facial do ator, já que esta pode estar sujeita a mais de uma interpretação.

\footnotetext{
Considerando o indivíduo por natureza incorporado ao contexto social, composto de outras pessoas e estímulos que emergem deste ambiente, algumas pesquisas neste campo tem associado a apresentação de faces aliada ao contexto, argumentando e evidenciando que o processo perceptivo de discriminação da expressão facial dificilmente ocorre em isolado e apontando que o contexto parece, inclusive, exercer influência significativa neste processo, principalmente tratando-se de afetividade (URTADO, 2020, p. 25).
}

A partir destas explanações, percebe-se que a participação do público na construção da obra é o ponto que une as teorias de Gombrich, McCloud e Kuleshov. Poderíamos citar outras pesquisas e teóricos, mas vamos nos limitar a esses apenas a título de base para o desenvolvimento de nossa análise do objeto de estudo deste artigo: a websérie $\mathrm{O}$ BemAmado e a produção de sentidos a partir da incompletude das figuras e das imagens.

\section{A PRODUÇÃO DA WEBSÉRIE}

A fim de organizar visualmente o desenvolvimento narrativo para criar os personagens, o ilustrador Eloar Guazzelli, convidado pela companhia para realizar os desenhos das figuras, criou um storyboard da obra.

O storyboard é um esboço da disposição das personagens em cada momento da cena, em vários quadros em sequência. Cada reação, fala ou movimento que o artista deseja expressar é rabiscado neste exercício visual que, no caso da websérie, permitiu experimentar diferentes traços, escalas e cores. É uma etapa de escolhas, recurso amplamente utilizado pelo cinema e que muito se assemelha com uma HQ. Esse recurso permite expressar graficamente respostas para algumas questões, tais como: em qual pose Odorico estará quando o cemitério for inaugurado? Qual será a expressão de seu rosto no 
dia em que discursará para a multidão? Dessa forma, o storyboard funciona como um "passeio gráfico" por cada cena, permitindo a realização de um mapa estrutural da obra.

Para Guazzelli, o storyboard é um momento de improvisação. É quando se tem uma ideia do que o personagem pode ser e coloca-se essa ideia em prática. Guazzelli conta que, na medida em que avançava nos desenhos para o storyboard da série, ele adquiria maior fluidez no traço, de modo análogo ao ator que improvisa pela primeira, segunda e terceira, até que entenda corporalmente certas características da personagem que interpreta. De acordo com o artista, este recurso foi fundamental para a concepção das figuras: "é uma escolha, é um caminho expressivo. Qual o estilo que vai carregar essa ideia de forma mais coerente ou até no sentido inverso, atenuando o impacto de uma história agressiva. É [uma] ferramenta básica da narrativa sequencial”.

O storyboard não só orientou escolhas estéticas mas também conduziu a produção material da série: o número de figuras a serem impressas e quantidade de articulações necessárias para movimentá-las também foram decididas a partir da criação desse mapa gráfico da obra. Pensando na produção de sentido das ações dos personagens na websérie, por meio da incompletude, vamos aprofundar a reflexão sobre as funções do storyboard na construção das figuras.

Os artistas Paco Parício e Pilar Amorós comentam que a escolha das articulações tem muita importância na produção de sentido para a ação de seus personagens em seus espetáculos. Em uma montagem teatral de onde partimos do trabalho com imagens planas e imóveis, tais articulações podem ser um registro metafórico fundamental da personagem: "O rei que ordena move seu braço real, este dragão agita o corpo e abre a boca, o vampiro voa abrindo sua capa” (AMORÓS; PARÍCIO, 200o, p. 87). A pouca capacidade de movimento destas figuras torna-se um recurso, pois seus deslocamentos estão repletos de significado.

\footnotetext{
O sofisticado apelo à nossa imaginação não é, de nenhum modo, o primeiro nem o mais elementar dos métodos para superar as limitações deste veículo; estas limitações são de duas espécies. Uma diz respeito ao que há de necessariamente inacabado em toda a representação bidimensional. (GOMBRICH, 2007, p. I76).
}

Odorico mexe nos documentos orçamentários da prefeitura e entende que não tem verba o suficiente para construir o cemitério. Ao folhear as páginas de suas pastas, utiliza- 
se uma mão de papel diretamente manipulada pelo ator/animador. $O$ enquadramento da cena não permite que vejamos o resto de seu corpo e, então, quando articulado, esse movimento que apenas sugere o movimento real, cria, naquele instante, a imagem mental de um Odorico capaz de mover as páginas da pasta por sua própria autonomia. Temos aqui nosso primeiro exemplo de produção de sentido decorrente da sobreposição de linguagens: o enquadramento esconde os truques de articulação do teatro de figuras, e ambos oferecem ao espectador a ilusão de movimento.

Este recurso permite que o artista escolha qual parte de determinada cena será vista pelo público. Ao posicionar o observador no exato lugar em que se quer, limita-se sua abrangência visual não só resumindo, mas conduzindo a mensagem que deve ser transmitida. A mídia tem se utilizado deste recurso há décadas, quando mostra edições de imagens e apresenta tais informações como fatos. Se for de seu interesse que uma manifestação de rua chame a atenção da população, mesmo que esta tenha sido pequena, basta mostrá-la em planos de câmera fechados, quando focamos as lentes em um detalhe da imagem. Caso contrário, as mesmas imagens serão mostradas em plano aberto, para que o público veja a falta de participantes no movimento.

Figura 7 - Braços móveis de Odorico folheiam os documentos orçamentários da prefeitura.

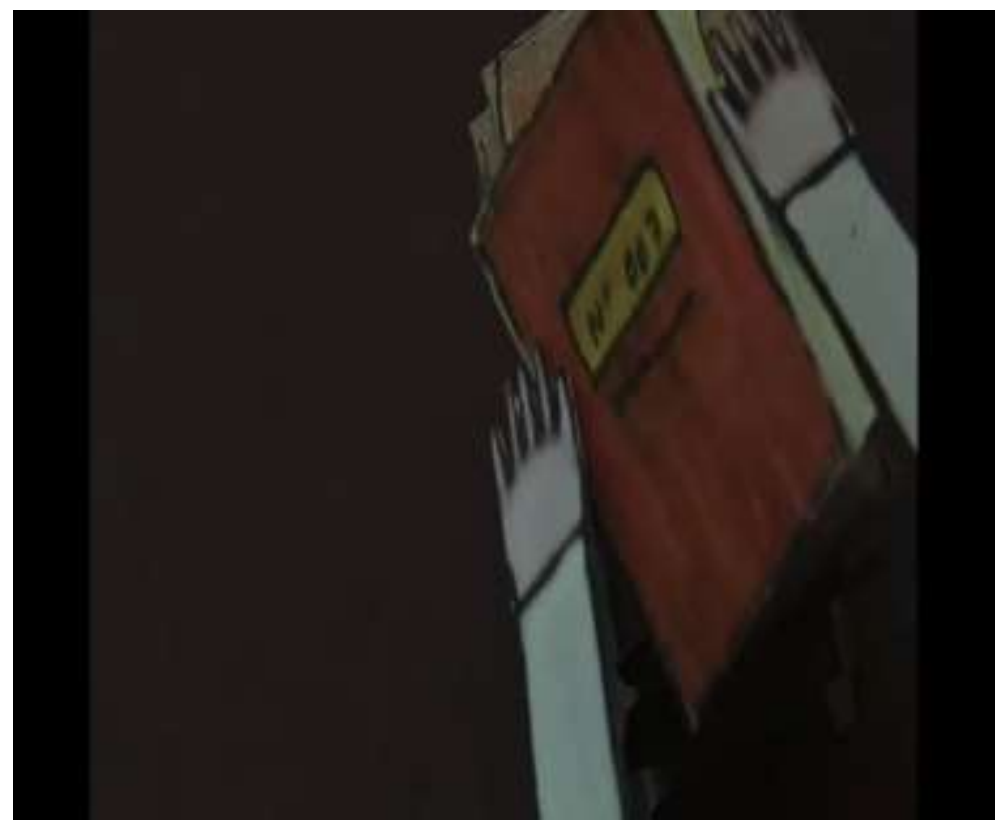

Fonte: https://www.youtube.com/watch?v=si47JYoeWw4\&t=51s (acesso em 04/or/2022) 
Figura 8 - Braços móveis de Odorico folheiam os documentos orçamentários da prefeitura.

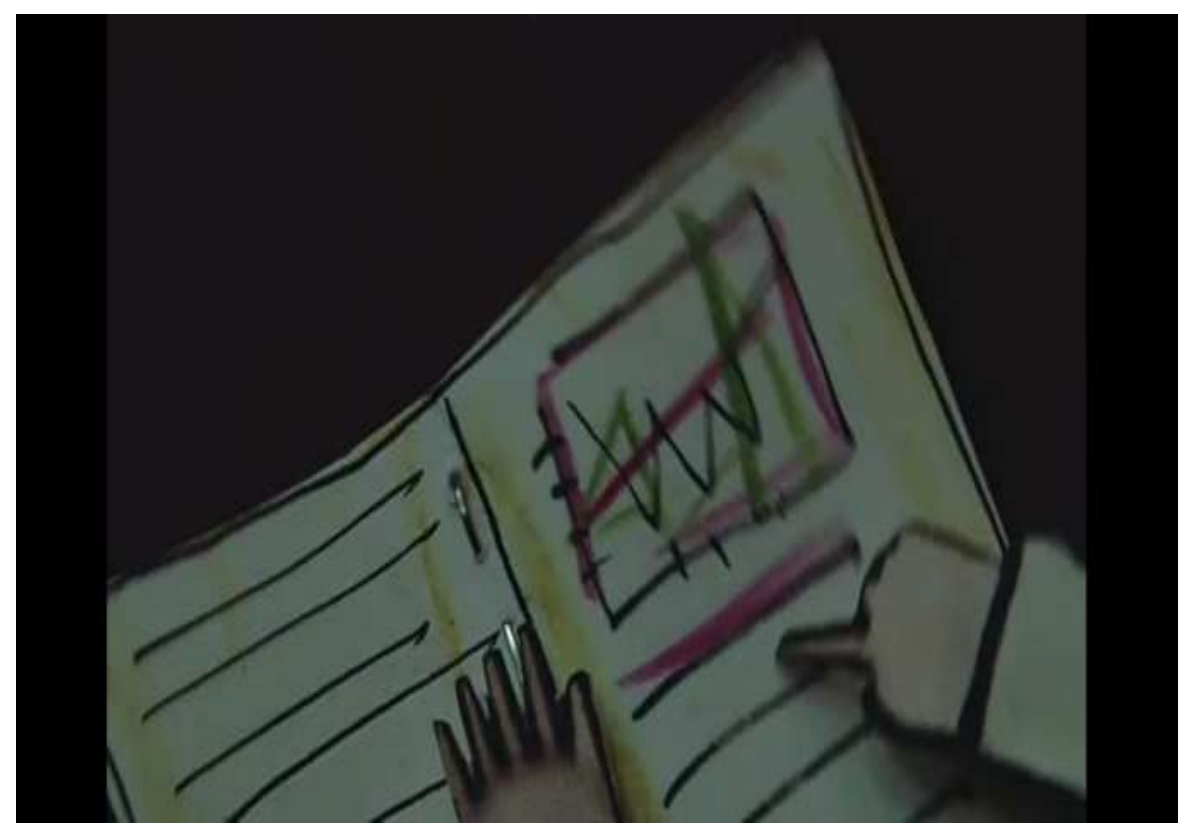

Fonte: https://www.youtube.com/watch?v=si47JYoeWw4\&t=51s (acesso em 04/or/2022)

Figura 9 - Odorico folheia os documentos orçamentários da prefeitura.

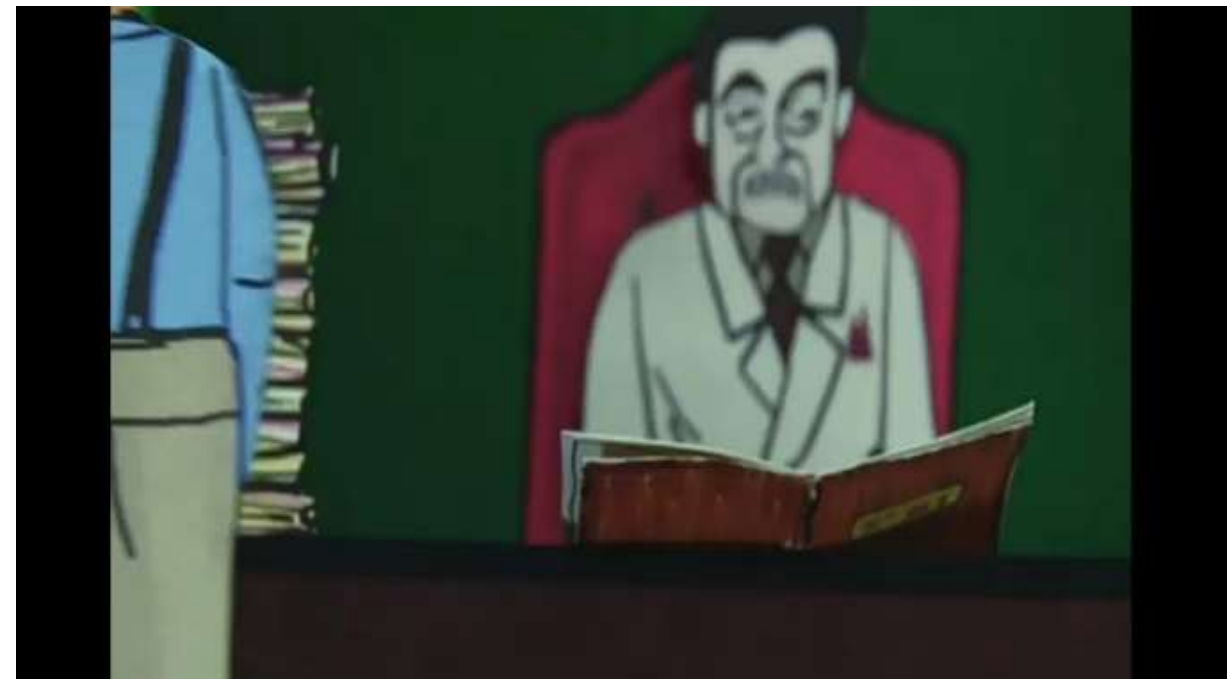

Fonte: https://www.youtube.com/watch?v=si47JYoeWw4\&t=51s (acesso em 04/or/2022)

No episódio 2, intitulado Odorico Prefeito, Odorico, o vigário e Dirceu Borboleta dividem a cena. Dirceu traz para Odorico os documentos financeiros da prefeitura para a avaliação orçamentária da construção do cemitério. A câmera acompanha a personagem 
que se desloca sendo animada por um ator/animador que em seguida o vira de costas para o espectador e de frente para a mesa de Odorico. Os documentos estão desenhados, na parte da frente da figura de Dirceu, cobrindo seu peito e parte de seu rosto. Ao virar-se de volta para o público e após um rápido corte de cena, os documentos desaparecem das mãos de Dirceu aparecendo em cima da mesa com Odorico. Esta cena exemplifica a edição de vídeo como recurso para a esconder o truque da troca de bonecos, pois primeiro foram gravadas cenas do boneco de Dirceu com os livros e em seguida, mantendo o boneco de Odorico na mesma posição, houve um corte para que pudéssemos retirar o boneco com livros e posicionar o boneco sem livros em frente a câmera, dando assim, a impressão de que a personagem soltou os livros em cima da mesa.

Figura ıo - Dirceu carrega documentos orçamentários da prefeitura.

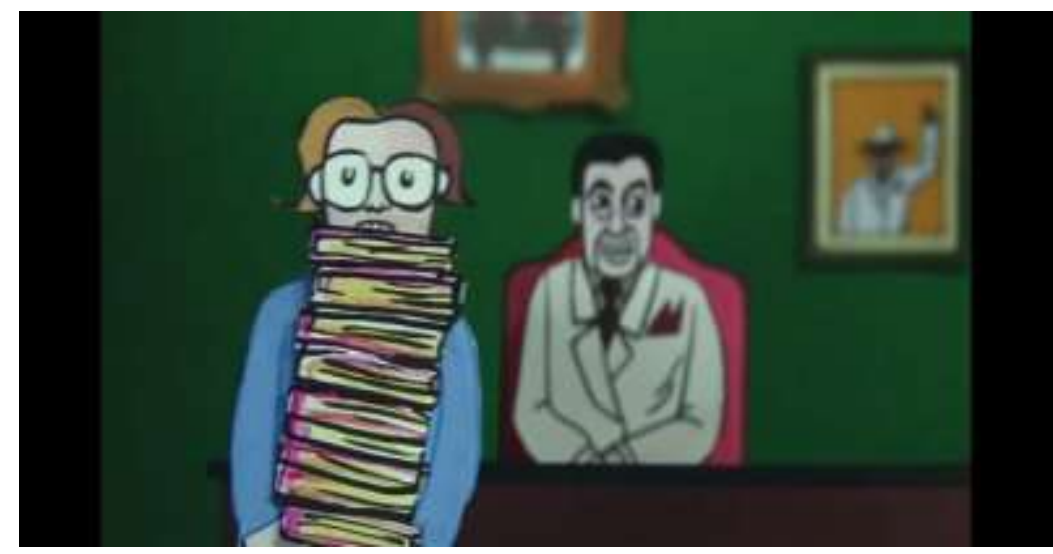

Fonte: https://www.youtube.com/watch?v=si47JYoeWw4\&t=51s (acesso em 04/or/2022)

Figura II - Dirceu carrega documentos orçamentários da prefeitura.

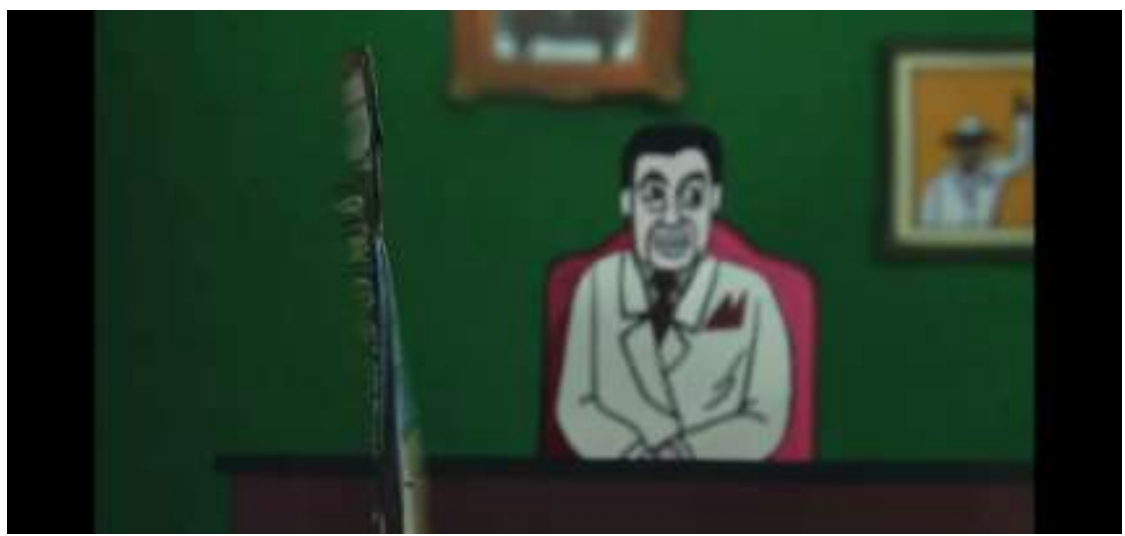

Fonte: https://www.youtube.com/watch?v=si47JYoeWw4\&t=51s (acesso em 04/or/2022) 
Figura 12 - Dirceu carrega documentos orçamentários da prefeitura.



Fonte: https://www.youtube.com/watch?v=si47JYoeWw4\&t=5is (acesso em 04/or/2022)

Estas linguagens se conectam na obra compondo os truques de cena que estruturam a produção de sentido, tornando-as assim, interdependentes. Quando a figura bidimensional surge em cena e sua personagem precisa realizar determinada ação com um objeto, este já está desenhado nela, pois seu formato a impede de carregar objetos. Para que a ação possa fazer-se presente, entra um recurso do cinema: a montagem. Durante o processo de filmagem da cena, trocamos uma figura com o objeto por uma figura sem objeto, solicitando, desta forma, a imaginação do espectador que agora precisa formar em sua própria mente a cena onde Dirceu deixa os livros sobre a mesa.

\section{CONSIDERAÇÕES FINAIS}

Cada uma das linguagens exploradas no processo de criação da websérie oferece recursos que funcionam como pistas que o espectador une a fim dar sentido à obra. A sequência, as figuras, o recorte, o enquadramento, todos eles fazem parte do quebracabeças de significados que o espectador irá montar, lembrando que o apelo à imaginação é parte fundamental da produção de sentido desta obra. A partir das reflexões expostas neste artigo, podemos observar que a série é conduzida através de sistemas de animação das figuras no vídeo, que são composições oriundas das mesclas dos recursos das linguagens utilizadas. Identificamos que a animação, a ilusão do movimento autônomo dos personagens, no nível da imagem, ocorre a partir de distintos processos: 
I. A movimentação da figura realizada em tempo real - Nesta possibilidade, a ação do ator repercute direta e simultaneamente na ação executada pelo personagem. Embora a ação seja capturada em tempo real, o espectador verá o resultado num tempo diferente, ou seja, na exibição do audiovisual.

2. A movimentação da figura num tempo fragmentado - Esta possibilidade é muito utilizada em filmes/efeitos que utilizam stop-motion. Nela, a construção sistêmica da ação do personagem é realizada por meio da captura de "fotos" que irão se justapor contiguamente, provocando a ilusão do movimento. Esse modo possibilita o trabalho do ator nas "elipses" de tempo entre as fotos.

3. A substituição da figura baseada em marcos de expressão gráfica (desenho) Nesta possibilidade, temos a representação de diferentes estados emocionais do personagem (transformação em salto), produzidos pelo uso de diferentes figuras dos mesmos personagens. Quando a cena exige uma troca rápida de humor ou de pose, utilizamos mais de uma figura da mesma personagem com expressões diferentes, substituindo umas pelas outras. Para que o público não veja a troca de figuras e complete a ação fragmentada da personagem com sua imaginação, cortes são realizados na sequência de imagens, fazendo com que a narrativa dê um pequeno salto de um momento para outro, escondendo assim, o truque. A sobreposição da linguagem das figuras e do audiovisual caracteriza esse sistema.

Figura 13 - Odorico toma posse como prefeito da cidade.

Figura I4 - Odorico toma posse como prefeito da cidade.
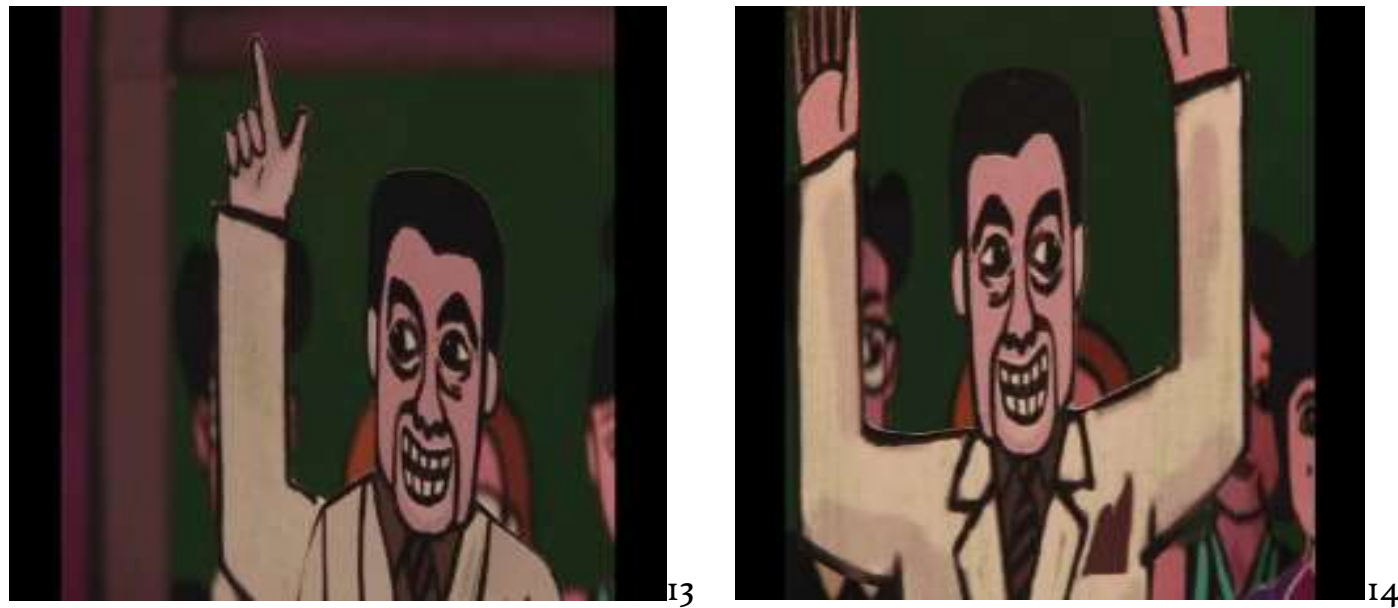

Fonte: https://www.youtube.com/watch?v=si47JYoeWw4\&t=51s (acesso em 04/or/2022) 
4. O movimento da câmera - Utilizando mudança de foco, zoom, panorâmicas, tilts, entre outros recursos, pode-se determinar a posição do observador em relação às figuras. A câmera ganha controle sobre este aspecto, direcionando o olhar do espectador para onde the aprouver. Durante os diálogos da websérie, por exemplo, geralmente a câmera aponta para as personagens que estão falando. Tendo em vista que não há articulação nas bocas das figuras, a convenção de a câmera apontar para o personagem falante colabora para o entendimento de quem está com a palavra (a seleção do que será visto pelo espectador é um recurso tanto do audiovisual quanto dos quadrinhos).

5. A inferência (imaginação) de movimentos, ações e expressões por parte do observador - Existe uma incompletude na composição do enquadramento, o qual seleciona alguns elementos para comporem o quadro, deixando outros de lado. Quando vemos uma figura caminhando em plano médio, da cintura para cima, inferimos que existam pernas que se movimentam, mesmo sem vê-las. Em seguida, se observarmos as pernas no plano seguinte, suporemos que sejam as pernas desse personagem. Para as figuras, a característica bidimensional limita suas capacidades motrizes. Quando combinada com os recursos do audiovisual, diversas possibilidades de movimento surgem: contando sempre com a inferência do espectador. Como vimos anteriormente, ao desenhar os braços de Odorico separados de seu corpo, permitimos que ele possa mexer nos documentos da prefeitura.

Assim, percebemos como as distintas linguagens utilizadas na produção audiovisual atuaram em consonância, por meio de arranjos sistêmicos, gerando sentidos tanto pela seleção das imagens quanto pelo modo como foram justapostas na edição. Percebemos também que, embora cada uma dessas linguagens utilizadas possuam especificidades, existem pontos, processos que as conectam, a começar pelo recurso bidimensional utilizado, pelos enquadramentos e pela perspectiva do ponto de vista oferecido ao observador. Este último, paulatinamente, é capaz de incitar um "sentimento de realidade" por meio da montagem:

A imagem fílmica suscita, portanto, no espectador um sentimento de realidade em certos casos suficientemente forte para provocar a crença na existência objetiva do que aparece na tela. (...) Duas características fundamentais da imagem resultam de sua natureza de reprodução objetiva do real. Em primeiro lugar, ela é uma representação unívoca: pelo fato do seu realismo instintivo, ela não extrai senão aspectos precisos e determinados, únicos no espaço e no tempo, da realidade. (MARTIN, 2005, p. 28-9) 


\section{REFERÊNCIAS BIBLIOGRÁFICAS}

AMORÓS, Pilar; PARÍCIO, Paco. Títeres y Titiriteros - El lenguaje de los títeres. $2^{\circ}$ ed. Huesca: Titiriteros de Binéfar, 2005. 165 p.

BOCK, Ana Maria; TEIXEIRA; Maria de Lourdes T; FURTADO, Odair. Psicologias Uma introdução ao estudo da psicologia. São Paulo: Saraiva, 2004. 464 p.

EISENSTEIN, Serguei. O sentido do filme. Tradução: Teresa Ottoni. Rio de Janeiro: Jorge Zahar Ed., 2002. 152 p.

GOMBRICH, E.H. Arte e ilusão: um estudo da psicologia da representação pictórica. Tradução: Raul de Sá Barbosa. $4^{\circ}$ ed., São Paulo: WMF Martins Fontes, 2007. 386 p.

MARTIN, Marcel. A linguagem cinematográfica. Tradução: Lauro Antônio e Maria Eduarda Colares. Lisboa: Dinalivro, 2005.

McCLOUD, Scott. Desvendando os Quadrinhos. Tradução: Marisa do Nascimento Paro. Ied. São Paulo: M. Books do Brasil, 2005. 244 p.

URTADO, Melina. Percepção de faces neutras com análise do contexto e efeito Kuleshov. 2020. IoIf. Universidade de São Paulo, São Paulo, 2020.

\section{REFERÊNCIAS DE VÍDEO}

CIA. CARAS DE BONECO. Os Bastidores de Sucupira Parte II. Disponível em: $\langle$ https://www.youtube.com/watch?v=utDdnsHWDOw\&t=365s $\rangle$. Acesso 13/or/ 2022.

Brainstorm Tutoriais. Porque o cinema usa 24 fps? Disponível em 〈https://www.youtube.com/watch?v=Ji9xiWdv7cE〉 Acesso 13/or/2022.

CIA CARAS DE BONECO. O Bem Amado. Disponível em https://www.youtube.com/watch?v=si47JYoeWw4\&t=51s. Acesso em I4/or/2022. 